Riccardo Alessandro - Maria Antonietta Di Bella - Anna Maria Flugy • Simona Fontana - Francesca Damiani - Chiara Corrado - Paolo Colomba • Matilde Todaro • Domenica Russo • Alessandra Santoro

Elise C. Kohn • Giacomo De Leo

\title{
Comparative study of T84 and T84SF human colon carcinoma cells: in vitro and in vivo ultrastructural and functional characterization of cell culture and metastasis
}

Received: 3 October 2005 / Accepted: 14 February 2006 / Published online: 13 April 2006

(C) Springer-Verlag 2006

\begin{abstract}
To better understand the relationship between tumor heterogeneity, differentiation, and metastasis, suitable experimental models permitting in vitro and in vivo studies are necessary. A new variant cell line (T84SF) exhibiting an altered phenotype was recently selected from a colon cancer cell line (T84) by repetitive plating on TNF- $\alpha$ treated human endothelial cells and subsequent selection for adherent cells. The matched pair of cell lines provides a useful system to investigate the extravasation step of the metastatic cascade. Since analysis of morphological differences can be instructive to the understanding of metastatic potential of tumor cells, we compared the ultrastructural and functional phenotype of T84 and T84SF
\end{abstract}

R. Alessandro $(\varangle) \cdot$ M. A. Di Bella $\cdot$ A. M. Flugy $\cdot$ S. Fontana

F. Damiani - C. Corrado · P. Colomba - G. De Leo

Dipartimento di Biopatologia e Metodologie Biomediche,

Sezione di Biologia e Genetica, Università di Palermo,

Via Divisi 83,

90133 Palermo, Italy

e-mail: ricale@unipa.it

Tel.: +39-091-6554600

Fax: +39-091-6554624

M. Todaro

Dipartimento di Discipline Chirurgiche ed Oncologiche,

Università di Palermo,

Palermo, Italy

D. Russo

Istituto di Biomedicina ed Immunologia

Molecolare "Alberto Monroy", Centro Nazionale delle

Ricerche,

Palermo, Italy

\section{A. Santoro}

Laboratorio di Ematologia,

Dipartimento di Ricerca Clinica e Biotecnologia,

A.O. "V.Cervello",

Palermo, Italy

E. C. Kohn

Molecular Signalling Section, Laboratory of Pathology, Center for Cancer Research, National Cancer Institute,

Bethesda, MD, USA cells in vitro and in vivo. The reported ultrastructural features evidence differences between the two cell lines; selected cells showed a marked pleomorphism of cell size and nuclei, shape, and greater surface complexity. These morphological differences were also coupled with biochemical data showing a distinct tyrosine phosphorylation-based signaling, an altered localization of $\beta$-catenin, MAPK, and AKT activation, as well as an increased expression in T84SF cells of $\mathrm{Bcl}-\mathrm{X}_{\mathrm{L}}$, a major regulator of apoptosis. Therefore, these cell lines represent a step forward in the development of appropriate models in vitro and in vivo to investigate colon cancer progression.

Keywords Colon carcinoma - Tumor cells ·

Ultrastructure $\cdot$ Metastasis $\cdot$ Apoptosis $\cdot B^{-}-\mathrm{X}_{\mathrm{L}}$

\section{Introduction}

Tumor cell heterogeneity with regard to morphological, biochemical, functional, and genetic features has been widely documented $[4,18,25,43]$. Metastasis, a major complication of cancer disease, is a highly selective process that favors the emergence of cell clones able to establish specific cell-cell and cell-matrix interactions, to resist to hypoxia and to immune response [18, 41, 46]. However, to better understand the relationship between tumor heterogeneity and metastasis, suitable experimental models permitting in vitro and in vivo studies are necessary. For this purpose, the selection and establishment inside a cell population of clones showing high metastatic potential can highlight specific molecular properties correlated with metastatic phenotype [44]. Our group has recently derived a novel metastatic variant cell line, termed T84SF, by a selection procedure based on repetitive plating of colon cancer cells on TNF- $\alpha$ activated human endothelial cells. The matched pair of cell lines provides a useful system to investigate the extravasation step of the metastatic cascade. T84SF cells displayed in vitro a higher proliferation rate and a more invasive behavior compared 
to the parental cells, while a greater number of metastatic colonies in nude mice formed in vivo [4].

Electron microscopy (EM), together with biochemical and immunological analysis, may greatly contribute to the problem of intraneoplastic heterogeneity [19]. The morphological aspects of cells, strictly related to their functional properties, are highly relevant to the full phenotypic characterization of neoplastic cells. EM studies have been helpful, for example, in evaluating the surface changes that occur in malignant progression, such as alterations of cellcell interactions, modifications of microvilli structure and distribution, as well as increase in the release of membrane vesicles. Vesicles shedding, which affects the ability of proliferating and invasive cancer cells to infiltrate and metastasize, is an active process $[6,55]$. Several studies have demonstrated that cancer cells release membrane vesicles containing proteinases and, as such, may aid in the metastatic process $[21,23]$. Vesicle membranes also contain surface antigens expressed on the plasma membrane [12]; they originate from domains of the plasma membrane selectively enriched in membrane components, including HLA class I molecules, $\beta 1$ integrins, membranebound matrix metalloproteinase (MMP)-9 [13], and apoptosis-inducing molecules [32].

Considerable insight into carcinoma progression has been obtained from studies of relevant cell adhesion molecules such as E-cadherin and catenins [57]. It is known that loss of E-cadherin expression is associated with more aggressive tumors and with the acquisition of a mesenchymal and dedifferentiated phenotype. $\beta$-catenin is normally localized to the cell membrane and is bound to E-cadherin thus composing cell adhesion structures important for epithelial integrity. Genetic alterations occurring during colon progression lead to a cytoplasmic and nuclear accumulation of $\beta$-catenin, where it acts as a transcriptional activator of genes involved in invasive growth and metastasis [27]. To find support of suitability of our in vitro model, we analyzed the expression patterns of $\beta$-catenin and E-cadherin in T84 cells and selected cells.

Aberration in regulation of apoptosis has been recognized as an important mechanism in oncogenesis and tumor progression [24]; we have previously demonstrated that T84SF cells showed a lower apoptotic index compared to parental cell line. In this paper, we identify $\mathrm{Bcl}_{\mathrm{L}} \mathrm{X}_{\mathrm{L}}$ as a promising molecular player in the augmented apoptosis resistance of selected cells.

In the present study, with the purpose to investigate the early phases of the extravasation process, electron microscopic and biochemical investigations have been performed using T84 and T84SF cell lines. We have particularly evaluated (a) the in vitro and in vivo ultrastructural features of T84 parental and T84SF selected cells; (b) the expression of cell adhesion molecules; (c) the MAPK (ERK 1/2) and AKT signaling, which occurs in the two cell lines; (d) the content of vesicles shed by T84 and T84SF; and (e) the expression of Bcl- $\mathrm{X}_{\mathrm{L}}$ and caspase- 3 .

The ultrastructural and biochemical data reported here show interesting differences between parental and selected cell line, which support the value of this model for a better understanding of the extravasation step of the metastatic cascade.

\section{Materials and methods}

\section{Cell culture}

T84 (ICLC, Genova, Italy) and T84SF human colon cancer cells were maintained in DMEM-F12 (BioWhittaker, Verviers, Belgium) supplemented with $10 \%$ fetal calf serum (FCS) (BioWhittaker), $100 \mathrm{U} / \mathrm{ml}$ penicillin and $100 \mu \mathrm{g} / \mathrm{ml}$ streptomycin (Euroclone, UK).

In vitro ultrastructural characterization of $\mathrm{T} 84$ and T84SF cell lines

For conventional transmission electron microscopy (TEM), confluent T84 and T84SF tumor cells were rinsed briefly in prewarmed phosphate-buffered saline (PBS) $\mathrm{pH} 7.5$ and then fixed as a pellet and in situ as an intact sheet by addition of a volume of $2.5 \%$ glutaraldehyde buffered in $0.1 \mathrm{M}$ sodium cacodylate buffer. After several washes with buffer, the cells were postfixed with $1 \% \mathrm{OsO}_{4}$ for $1 \mathrm{~h}$ at $4^{\circ} \mathrm{C}$, rinsed and dehydrated in a graded ethanol series, gently scraped and then embedded in epoxy resin. Ultrathin sections were stained with uranyl acetate and lead citrate and finally examined under a Philips CM10 electron microscope at $80 \mathrm{kV}$. The ultrastructure features were evaluated by analysis of at least 50 cells of the two cell lines.

Ultrastructural characterization and gelatinase content of vesicles

For the preparation of the vesicles, subconfluent T84 and T84SF cells were washed with PBS then successively incubated in serum-free DMEM-F12 for $24 \mathrm{~h}$ and in $10 \%$ FCS growth medium for $3 \mathrm{~h}$ to stimulate vesicles shedding [53]. Culture media were then collected and centrifuged at 4,500 rpm for $10 \mathrm{~min}$ to remove cell debris. The cell-free supernatants were further centrifuged for $3 \mathrm{~h}$ at $4^{\circ} \mathrm{C}$ at 27,000 rpm. Pelleted vesicles were resuspended in PBS, and the amount of isolated vesicles was determined by measuring protein concentration using bovine serum albumin (BSA; Sigma Chemical, St. Louis, MO, USA) as a standard.

For analysis of the ultrastructural morphology of the shed vesicles, the vesicles pellet was resuspended in PBS and then applied to collodion-coated grids. After washing, the vesicles were negatively stained with uranyl acetate or $1 \%$ phosphotungstic acid and examined by transmission electron microscopy.

For zymographic analysis of vesicle-associated gelatinases, vesicles were obtained by stimulating T84 and T84SF cells with gelatin Sepharose-treated MMP-free serum, to avoid MMP contamination from serum [13]. 
Zymography was performed using $8 \%$ polyacrylamide gel containing $0.1 \%$ gelatin. Vesicle samples were diluted in sodium dodecyl sulfate-polyacrylamide gel electrophoresis (SDS-PAGE) sample buffer in nonreducing conditions without heating. After electrophoresis, gel was washed twice for $30 \mathrm{~min}$ in $2.5 \%$ Triton X-100 at room temperature and incubated overnight in $50 \mathrm{mM}$ Tris- $\mathrm{HCl}, \mathrm{pH} 7.5$, $10 \mathrm{mM} \mathrm{CaCl}_{2}, 150 \mathrm{mM} \mathrm{NaCl}$, at $37^{\circ} \mathrm{C}$. Gel was stained in Coomassie Blue R 250 for $1 \mathrm{~h}$. Gelatinase activities were visualized as clear bands, on a stained background. As standards for gelatinases, a cell culture media from human fibroblasts treated with TPA (Sigma, St. Louis, $\mathrm{MO})$, was used.

Ultrastructural characterization of metastasis

T84 and T84SF metastasis were obtained by injecting viable single cells suspensions $\left(2 \times 10^{6}\right)$ into tail veins of athymic male nude mice [4].

Anesthetized animals were perfused with an isotonic buffered saline solution containing $2 \%$ dextran for $10 \mathrm{~min}$ followed by a $15 \mathrm{~min}$ treatment with $2.5 \%$ glutaraldehyde buffered in $0.1 \mathrm{M}$ sodium cacodylate. Lungs were removed, cut into small pieces and immersed in the same solution for $2 \mathrm{~h}$. After rinsing in cacodylate buffer, biopsies were postfixed in $1 \% \mathrm{OsO}_{4}$ for $1 \mathrm{~h}$, and finally embedded in Epoxy resin. Ultrathin sections were cut, stained, and analyzed at the transmission electron microscope.

Reverse transcription-polymerase chain reaction analysis

Total RNA from subconfluent cells was isolated with the Rneasy Mini kit (QIAGEN, Hilden, Germany) according to the manufacturer's instructions. Five micrograms of total RNA from each cell line were used for first strand cDNA synthesis using the 1st Strand cDNA Synthesis kit (Amersham, Little Chalfont, UK). One-tenth of the reverse transcribed cDNA was amplified with the following polymerase chain reaction (PCR) primer sets: $5^{\prime}$-AAA TGTCTCAGAGCAACCG-3' (sense), 5'-TACGCTTTC CACGCACAGT-3' (antisense) for Bcl-X $\mathrm{X}_{\mathrm{L}}$; 5'-GAGGA GAGCGGTGGTCAAAG-3' (sense), 5'-GTTCAGGGA GCTCAGACTAG-3' (antisense) for E-Cadherin; and 5'CAAGAGATGGCCACGGCTGCT-3' (sense), 5'-TCCTT CTGCATCCTGTCGGCA-3' (antisense) for $\beta$-actin (used as an internal standard). Standard amplifications were performed with a total of 40 cycles at an annealing temperature of $56^{\circ} \mathrm{C}$. All the oligonucleotides were designed to recognize a unique sequence for each mRNA. The PCR products were separated in 1\% agarose gels. The expected product sizes were 467, 361, and $275 \mathrm{bp}$ for Bcl- $X_{L}, E-C a d h e r i n$, and $\beta$-actin, respectively.
Western blot analysis

T84 parental cell line and T84SF cells grown at subconfluence were washed with PBS and resuspended in lysis buffer $(300 \mathrm{mM} \mathrm{NaCl}, 50 \mathrm{mM}$ Tris- $\mathrm{HCl} \mathrm{pH}$ 7.6, $0.1 \%$ Triton, $1 \mathrm{mM}$ PMSF, $10 \mu \mathrm{g} / \mathrm{ml}$ Leupeptin, $10 \mu \mathrm{g} / \mathrm{ml}$ Aprotinin, $4 \mathrm{mM}$ EDTA, $2 \mathrm{mM}$ sodium orthovanadate, $10 \mathrm{mM} \mathrm{PP}_{\mathrm{I}}, 100 \mathrm{mM} \mathrm{NaF}$ ) on ice for $1 \mathrm{~h}$. The cell lysates were clarified at high-speed centrifugation for $15 \mathrm{~min}$, and an aliquot of the supernatant was assayed to determine protein concentration by Bradford method. Proteins were separated by a $6 \%$ SDS-PAGE and transferred to nitrocellulose membrane (Protran Schleicher and Schuell, Dassel, Germany). The membrane was incubated in block solution (1 M glycine, $1.25 \%$ dry milk, $0.1 \%$ ovalbumin) and probed overnight at $4{ }^{\circ} \mathrm{C}$ with specific antibodies against Bcl- $_{\mathrm{L}}$ (H5 mouse IgG1, Santa Cruz Biotechnology, Santa Cruz, CA, USA), caspase-3 (rabbit polyclonal, Santa Cruz Biotechnology), p44/42 MAP (Cell Signalling Technology, Beverly, MA, USA), phospho-p44/42 MAP kinase (Cell Signalling Technology), total AKT (rabbit polyclonal, Cell Signalling, Danvers, MA, USA), pAKT (mouse monoclonal, Becton and Dickinson, Franklin Lakes, NJ, USA), E-Cadherin (G10 mouse IgG1, Santa Cruz Biotechnology), and $\beta$-catenin (mouse monoclonal, Santa Cruz Biotechnology). After three washes with WS, the membrane was incubated with proper horseradish peroxidase-conjugated secondary antibody, and proteins were detected by the enhanced chemiluminescence detection system (Super Signal, Pierce, Rockford, IL, USA).

\section{Confocal microscopy}

Cells were allowed to attach for $3 \mathrm{~h}$ to glass coverslips precoated with $25 \mathrm{nM}$ collagen IV (Sigma Chemical). They were then fixed in $3.7 \%$ formaldehyde in PBS, permeabilized with $0.5 \%$ Triton X-100, and blocked with $1 \%$ BSA (Fraction V) (Sigma Chemical) in PBS for $1 \mathrm{~h}$. Coverslips were incubated with $\beta$-catenin antibody (mouse monoclonal, Becton and Dickinson) at a 1:200 dilution in PBS overnight at $4{ }^{\circ} \mathrm{C}$. Antibody-treated cells were washed in PBS and incubated with Alexa-Fluor 594 conjugated with goat IgG anti-mouse antibody (Molecular Probes, Eugene, OR, USA) at a 1:500 dilution in PBS for $1 \mathrm{~h}$. Coverslips were washed and mounted using Vectashield with DAPI (Vector Labs, Burlingame, CA). The cells were examined with the use of a Nikon Diaphot-TDM (Eclipse 200) confocal microscope equipped with a $65 \times$ objective.

Immunohistochemistry and immunofluorescence

Immunohistochemical stainings were performed on $5-\mu \mathrm{m}$ thick paraffin sections of mouse lung metastasis obtained after tail vein injections of T84 and T84SF human colon cancer cell lines. Deparaffinized sections were permeabilized in PBS with $0.1 \%$ Triton X-100 for $10 \mathrm{~min}$ and then incubated with $3 \%$ BSA to block the unspecific staining. 
After several washes in PBS, sections were incubated overnight at $4^{\circ} \mathrm{C}$ with specific antibody against Bcl- $\mathrm{X}_{\mathrm{L}}$ (1:50 dilution; H5 mouse IgG1, Santa Cruz Biotechnology). After two rinses in PBS, sections were incubated for $30 \mathrm{~min}$ at room temperature with biotinilated anti-mouse immunoglobulins (Dako LSAB2 Kit, Dako, Carpinteria, CA, USA) and then incubated with streptavidin peroxidase for $30 \mathrm{~min}$ (Dako LSAB2 Kit, Dako). Staining was detected by AEC (3-Amino-9-ethylcarbazole) as a colorimetric substrate. Nuclei were counterstained using aqueous hematoxylin (Dako).

For immunofluorescence studies, T84 and T84SF cells were plated at $3 \times 10^{5}$ cells/well on coverslips previously coated with gelatin $(2 \mu \mathrm{g} /$ well $)$. After $1 \mathrm{hr}$ of adhesion, cells were washed with PBS, fixed in $3.7 \%$ paraformaldehyde for $10^{\prime}$, permeabilized for $5^{\prime}$ in $0.5 \%$ Triton X-100, and blocked in $1 \%$ BSA for $60^{\prime}$. Cells were incubated with an anti-phosphotyrosine antibody (PY20, Santa Cruz Biotechnology) for $60^{\prime}$ at $37^{\circ} \mathrm{C}$, washed three times with $\mathrm{PBS}$, and then incubated with the fluorescein-conjugated secondary antibody for $60^{\prime}$. After several washes, coverslips were mounted in moviol and viewed by fluorescence microscopy (Olympus BX50).

\section{Results}

Ultrastructural analysis of T84 and T84SF cell lines

Electron microscopy analysis of T84 and T84SF colon carcinoma cells confirmed and extended the previously described data on morphological differences between the two cell lines [4]. The prominent difference observed was the pronounced cellular and nuclear polymorphism.

T84 cells showed a spindle or polygonal shape. The nuclei displayed homogeneous chromatin and one or two round or elongated nucleoli. The cytoplasm contained elements of rough endoplasmic reticulum, some mitochondria, and free scattered ribosomes. Lipid droplets and glycogen granules were observed in small quantities (Fig. 1a-c). The cells were connected by desmosomes and some junctions appeared as long regions of adhesion even though no specific structure was evident. The cell surfaces exhibited prominent processes and sometimes long cytoplasmic projections; microvilli were pleomorphic in both size and distribution (Fig. 1c,d).

T84SF cells, harvested in suspensions or in a monolayer, revealed a significant heterogeneity in cell shape and size and were characterized by a high nucleus-to-cytoplasm ratio (Fig. 2a,c,i). Nuclei were enlarged and well-distinguished, often irregular in shape and highly segmented with crude chromatin structure; the nuclear profile was
Fig. 1 Ultrastructural features of T84 cells. Cells range from oval to spindle shape $(\mathbf{a}, \mathbf{b})$ and are connected to each other by cell junctions (arrowheads) (d). The cytoplasm contains some lipid droplets and organelles. Note the long cytoplasmic projections (a,c). Scale bars $1 \mu \mathrm{m}$ $(\mathbf{a}, \mathbf{d}), 2 \mu \mathrm{m}(\mathbf{b}, \mathbf{c})$

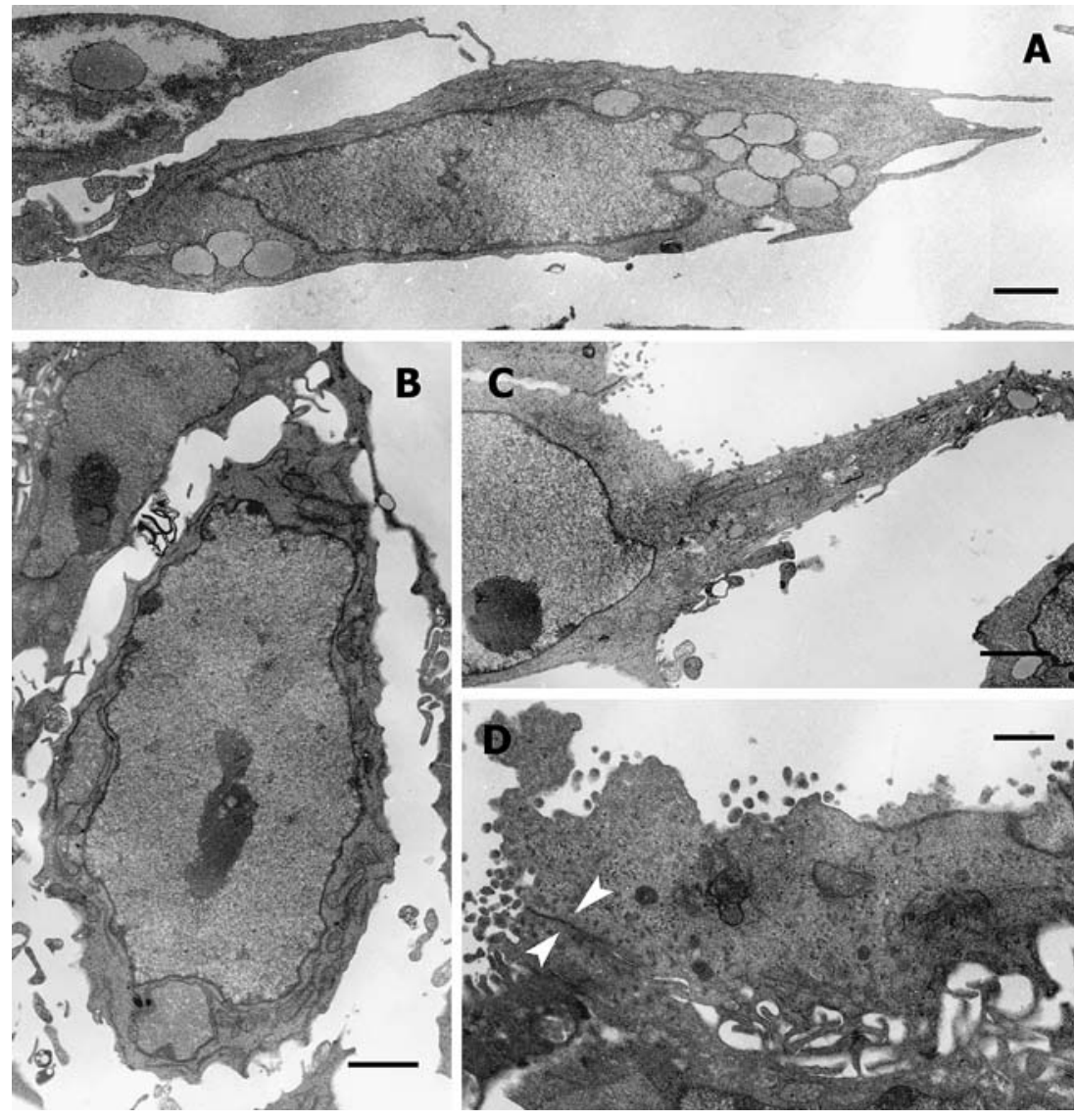


sometimes indented by a nuclear pocket (Fig. 2b). One or two prominent nucleoli with evident fibrillar centers could be identified (Fig. 2a,c). The cytoplasm was reduced and showed few cell organelles. T84SF had well-developed lysosomal granules in their cytoplasm and numerous lipid droplets; mitochondria were more irregular and swollen. The cytoplasm often showed electron lucent cleft-like space, multivesicular bodies, or vacuoles and microfilament bundles (Fig. 2d,i). Myelin figures were also encountered (Fig. 2a,i). Several cells showed some crystal-like intracellular structures (Fig. 2e).

T84SF cells displayed a very convoluted cell surface forming many interdigitations with neighboring cells (Fig. 2a,i); these were connected by regular junctional complexes as desmosomes or regions of adhesion occurring along the lateral borders. Networks of intermediate filaments were anchored to the desmosomes (Fig. 2g,h).

Cell surfaces exhibited abundant, branched, and randomly orientated protrusions, as well as an increased number of pleomorphic microvilli making contact with each other. In many cases, intracellular lumina with welldeveloped microvilli were formed (Fig. 2f,i).
These differences in cellular and nuclear polymorphism and distribution of cytoplasmic organelles in the two cell lines are summarized in Table 1.

Ultrastructural features and proteolytic activity of T84- and T84SF-released vesicles

The most striking characteristic of T84SF was the amount of vesicles shed from the plasma membrane and also found in the peripheral cytoplasm (Figs. 2d and 3a). As shown in Fig. 3b, purified vesicles analyzed by TEM with negative staining appeared homogeneous in form, with a roughly spherical shape and a size ranging between 90 and $140 \mathrm{~nm}$. No morphological differences between the vesicles collected by the two cancer cell lines were observed by ultrastructural analysis, although T84SF cell consistently released a greater amount of vesicles compared to T84 parental cells.

The presence of matrix metalloproteinases in T84 and T84SF vesicles was analyzed by gelatin zymography (Fig. 4) to assess whether the invasive nature of the T84SF cells was correlated with an increased release of vesicle-
Fig. 2 TEM view of T84SF cells. Neoplastic cells present irregularity in size and shape, different cell projections and abundant microvilli, well-demarcated enlarged nuclei often irregular in shape, and prominent nucleoli $(\mathbf{a}, \mathbf{c})$. Nuclear pockets can be observed (b). In the cytoplasm, lipid droplets, electron-lucent cleft-like spaces $(\mathbf{a}, \mathbf{i})$, microfilament bundles, microtubuli (d) and some myelin figures can be observed (arrows) (a,i). Details of junctional complexes and desmosomes between lateral membranes are shown in $\mathbf{g}$ and $\mathbf{h}$; intracellular lumina, where numerous microvilli are projecting into the lumen, can be clearly seen (f,i). Figure e shows a detail of a cytoplasmic paracrystalline inclusion. Scale bars $2 \mu \mathrm{m}$ (a), $1 \mu \mathrm{m}$ (c,f,i), $0.5 \mu \mathrm{m}$ $(\mathbf{b}, \mathbf{d}), 0.4 \mu \mathrm{m}(\mathbf{e}, \mathbf{g}, \mathbf{h}) . l$ Lumen

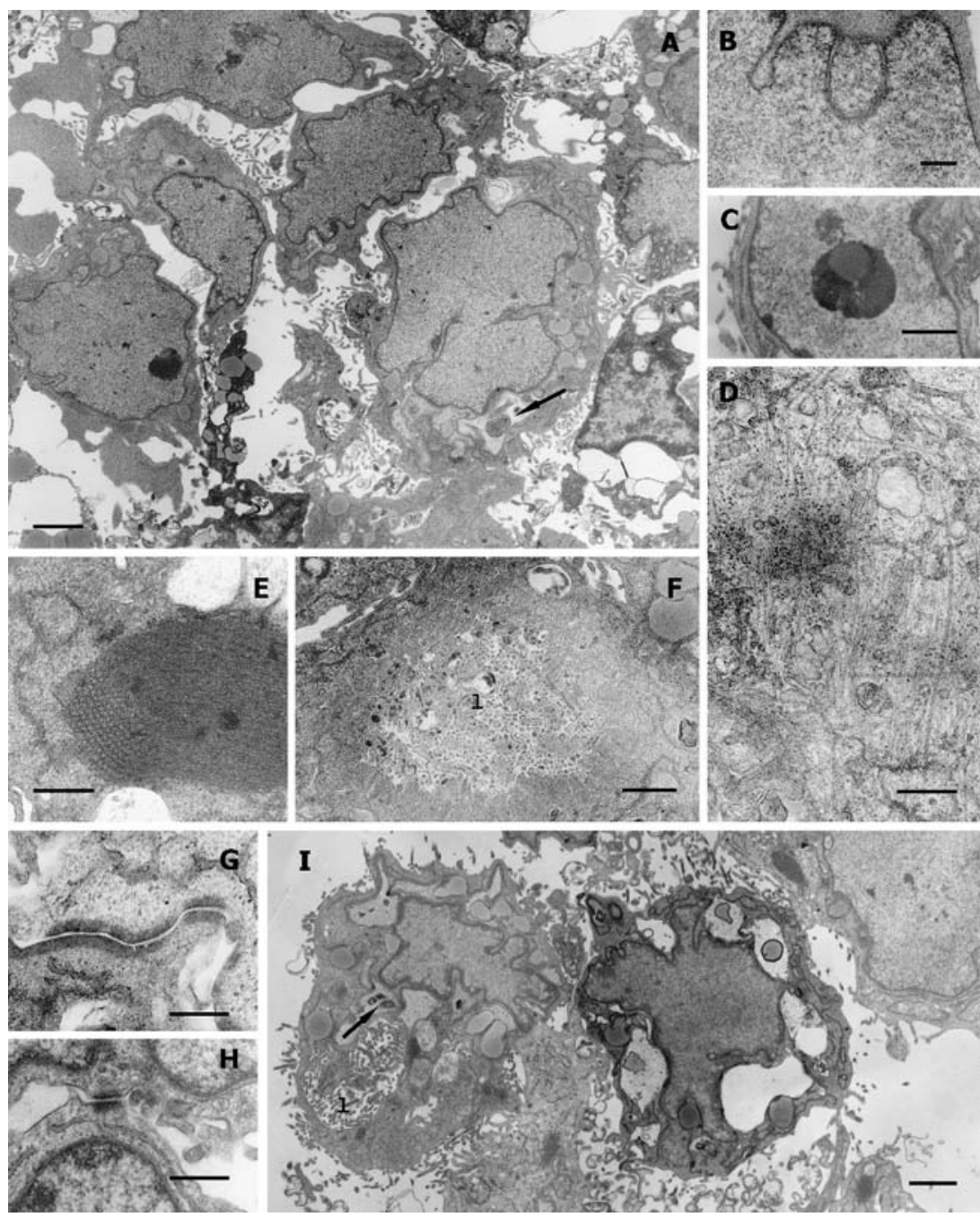



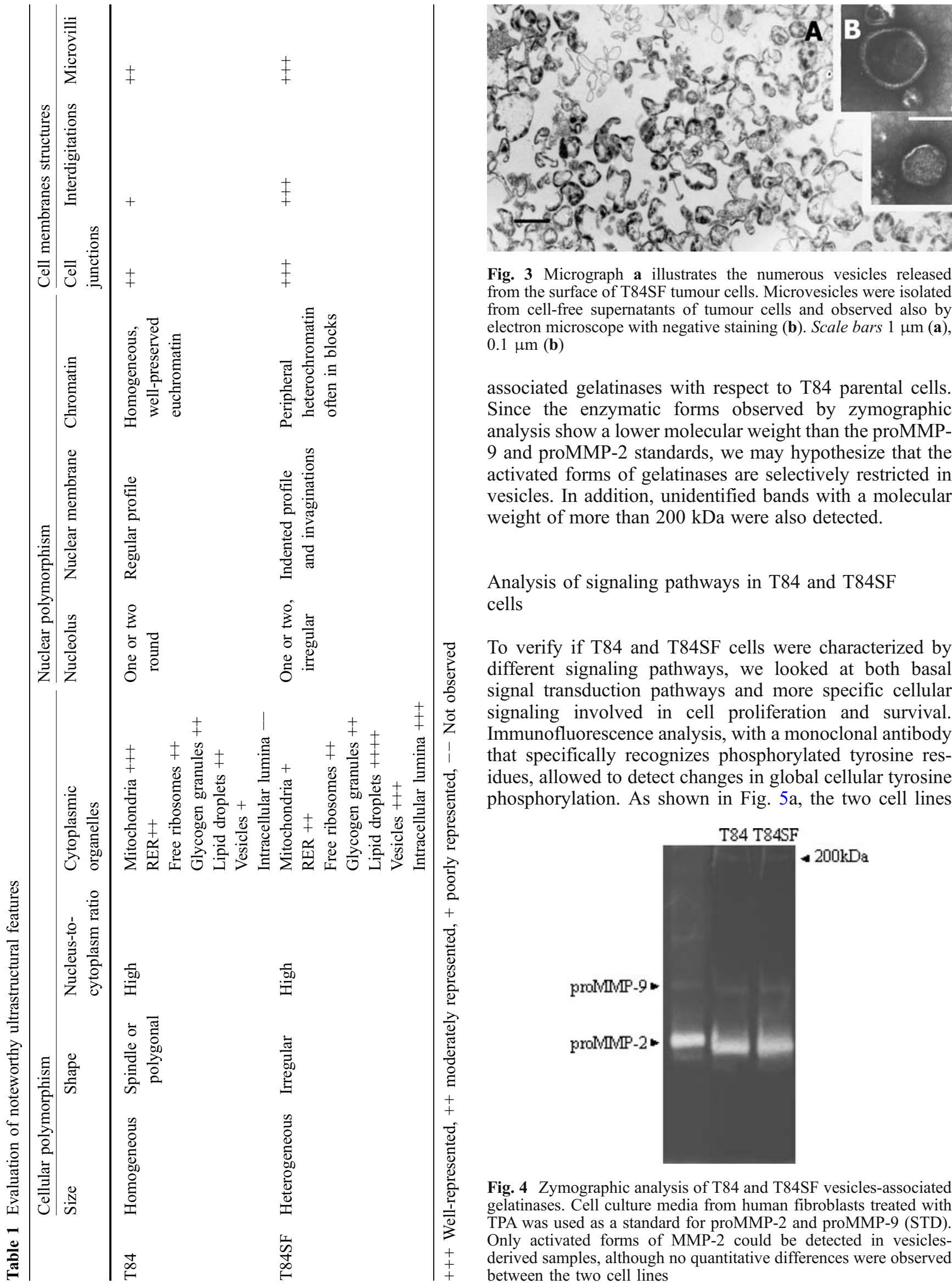

Fig. 3 Micrograph a illustrates the numerous vesicles released from the surface of T84SF tumour cells. Microvesicles were isolated from cell-free supernatants of tumour cells and observed also by electron microscope with negative staining (b). Scale bars $1 \mu \mathrm{m}$ (a), $0.1 \mu \mathrm{m}(\mathbf{b})$

associated gelatinases with respect to T84 parental cells. Since the enzymatic forms observed by zymographic analysis show a lower molecular weight than the proMMP9 and proMMP-2 standards, we may hypothesize that the activated forms of gelatinases are selectively restricted in vesicles. In addition, unidentified bands with a molecular weight of more than $200 \mathrm{kDa}$ were also detected.

Analysis of signaling pathways in T84 and T84SF cells

To verify if T84 and T84SF cells were characterized by different signaling pathways, we looked at both basal signal transduction pathways and more specific cellular signaling involved in cell proliferation and survival. Immunofluorescence analysis, with a monoclonal antibody that specifically recognizes phosphorylated tyrosine residues, allowed to detect changes in global cellular tyrosine phosphorylation. As shown in Fig. 5a, the two cell lines

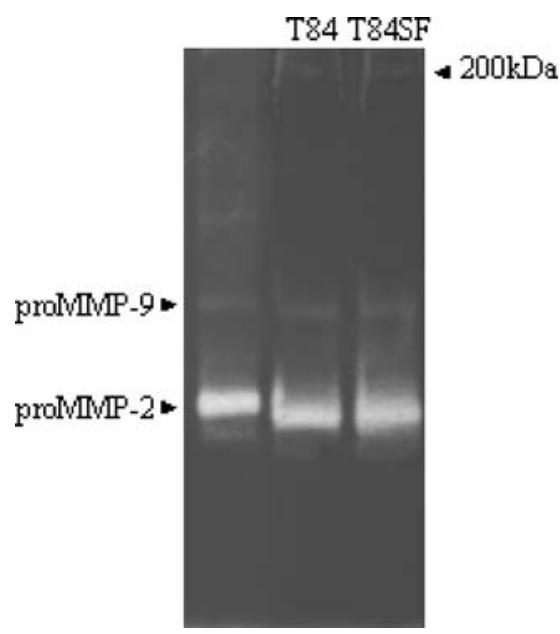

Fig. 4 Zymographic analysis of T84 and T84SF vesicles-associated gelatinases. Cell culture media from human fibroblasts treated with TPA was used as a standard for proMMP-2 and proMMP-9 (STD). Only activated forms of MMP-2 could be detected in vesiclesderived samples, although no quantitative differences were observed between the two cell lines 
displayed a different basal intensity and localization of tyrosine-phosphorylated proteins.

Since several reports have indicated activation of extracellular signal-regulated kinase (ERK) in several human cancer cell lines, including colon cancer cell lines $[34,50]$, we next examined whether the basal ERK signaling pathway was differentially activated in T84SF selected cells compared to T84 parental cells. To determine whether ERK was activated, T84 and T84SF cells were cultured up to $60 \%$ of confluence; whole cell extracts were prepared and immunoblotted with antibodies specifically recognizing the phosphorylated and active forms of ERK1/2. Figure $5 \mathrm{~b}$ shows the almost exclusive phosphorylation of ERK1/2 in T84SF cells compared to parental cells (upper panel). Total ERK proteins showed a slight increase of $15 \%$ in T84SF cells with respect to T84 cells (Fig. 5b, lower panel).

Another critical intracellular signaling, often deregulated in various human malignancies, is the AKT/PKB signal transduction pathway that is involved in the regulation of cell survival [20]. Our Western blot analysis, using antibodies against the phosphorylated and active forms of AKT, shows a $20 \%$ increase of the phosphorylated form of AKT in T84SF cells compared to the parental cells (Fig. 5c,

$\mathrm{T} 84$

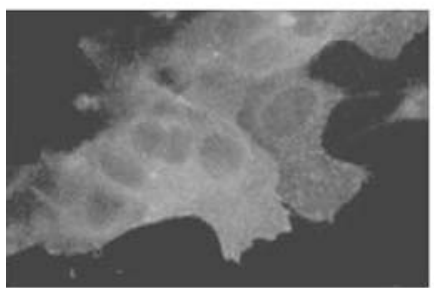

A

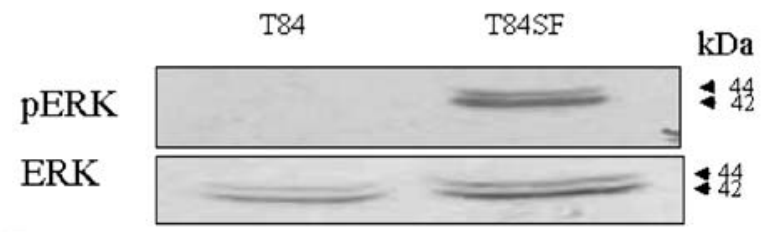

B

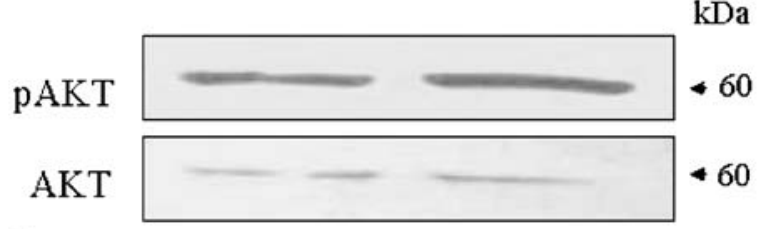

$\mathrm{C}$

Fig. 5 Analysis of proteins involved in signalling pathways of T84 and T84SF cells. a Immunofluorescence analysis of tyrosine phosphorylated proteins in T84 parental and selected cells shows a clear difference in the intensity and localization of $\mathbf{b}$ Western blot analysis of phospho ERK1/2 (upper panel) and total ERK1/2 (lower panel) in T84 and T84SF cells. One hundred micrograms of cell lysates was loaded for both T84 and T84SF cells. The Western blot results presented are representative of at least three different experiments upper panel). The amount of total AKT did not change between the two cell lines (Fig. 5c, lower panel).

Ultrastructural analysis of lung metastasis

Electron microscopy analysis of the tumor T84 and T84SF cells in athymic mice confirmed the histological aspects of colon carcinoma metastatic foci and added several ultrastructural details on differentiative features of colon histological organization (Fig. 6).

T84SF carcinoma cells formed cellular nests consisting of closely apposed oval cells with large, centrally located nuclei; these showed oval or irregular shape and they were frequently indented. The cells exhibited high nuclear-tocytoplasmic ratios, with one or two nucleoli sometimes marginally attached to the nuclear profiles, and the chromatin was visible as distinct amount of peripheral heterochromatin (Fig. 6a,b). Some cells showed a columnar shape forming a tubular atypical gland (Fig. 6b); small nodular aggregates with a well-developed basal lamina at the base could be seen inside a larger one (Fig. 6c). In metastatic foci formed by T84SF cells, the cell borders were in contact with each other (Fig. 6a,c), while in T84 cells there was ultrastructural discontinuity with pericellular space or gaps between adjacent cells (Fig. 6d,e). However, in both cell types, the apico-lateral junctional complexes between adjacent cells were well-developed; tight junctions, intermediate junctions, and desmosomes were frequently formed (Fig. 7a-c).

Several peculiar aspects indicative of glandular epithelial differentiation were observed in metastasis formed by T84 parental and T84SF selected cells. The presence of numerous intercellular lumina, lined by junctions, could be frequently detected (Fig. 7b,c). On the luminal surface, the apical portion of the cells showed well-developed microvilli with a central core of filaments (Fig. 7b-d). Sometimes microvilli presented a covering of glycocalyceal bodies or filaments and granules (Fig. 7b,c); sometimes interdigitating microvilli were observed deeply indenting the adjacent cell membrane, and apical protrusions like bleb or blunt pseudopod-like projections could be seen on the cell surface (Fig. 7e,h,i). Intercellular lumina were of different sizes, sometimes too small to be easily recognized, sometimes so large to contain cellular debris and cellular remnants or whole cells (Fig. 7c). The luminal space was filled with a large variety of structures like flocculent and secretory materials and particles (Fig. 7b,c). Microvilli were also observed at the surface of intracytoplasmic lumen found entirely within a single cell (Fig. 8b).

The cells contained abundant mature organelles, such as Golgi complex, rough endoplasmic reticulum, and numerous free ribosomes throughout the cytoplasm; numerous round mitochondria with transverse parallel cristae occupied over $60 \%$ of the cytoplasm; however, they appeared poorly preserved (note washed-out matrix) (Fig. 7f).

Dense core granules, vesicles, multivesicular bodies, lysosome-like structures, and lamellar bodies were also present (Fig. 7f,g). 
Fig. 6 Lower power view of metastasis foci observed in the lung of athymic nude mice injected with T84SF $(\mathbf{a}, \mathbf{b}, \mathbf{c})$ or T84 cells (d,e). T84SF tumor cells are closely attached to each other and can have a columnar shape; widening of the intercellular spaces can be observed between T84 cells. A small confined nodular aggregate, delimited by an evident basal lamina (arrowheads), is shown inside a metastatic nest (c). Scale bars $1 \mu \mathrm{m}(\mathbf{a}, \mathbf{b}, \mathbf{c})$, $2 \mu \mathrm{m}(\mathbf{d}, \mathbf{e})$
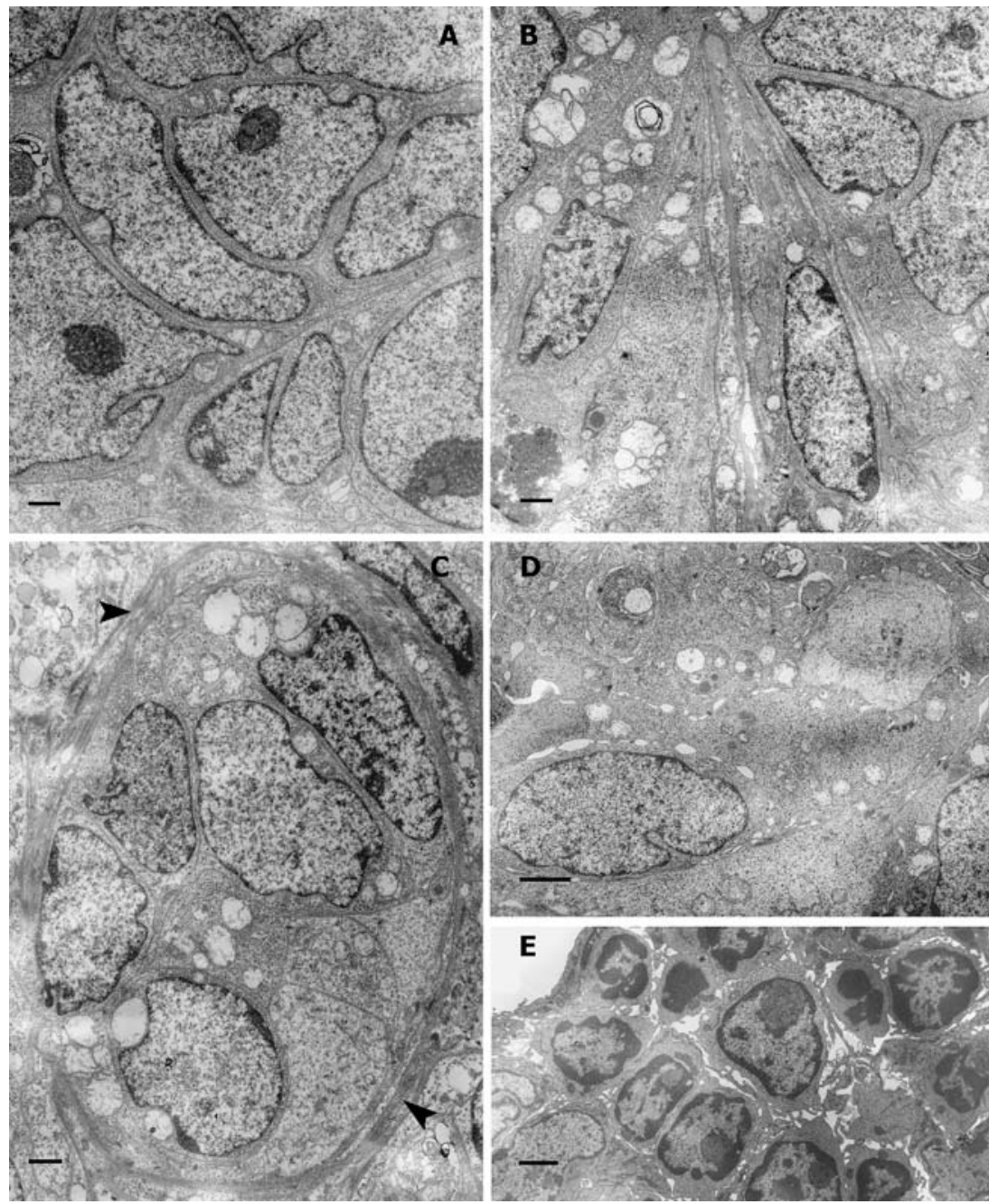

Both in the T84 and T84SF foci, cells in division could be observed at different phases, but the number of mitotic figures observed was increased in the T84SF cell line; desmosomal junctions were maintained in rounded tumor cells during mitosis (Fig. 8a).

The most notable difference found between the two carcinoma cells was the occurrence of centrosomal amplification; T84SF cells displayed abnormality including supernumerary centrioles that were, in fact, observed loosely dispersed in the cytoplasm during interphase (Fig. 8b).

E-cadherin and $\beta$-catenin expression in T84 and T84SF cell lines

Next, we analyzed whether the observed histopathological patterns of tumor growth were accompanied by in vitro alterations in the expression patterns and localizations of two important molecules involved in cell-cell adhesion: Ecadherin and $\beta$-catenin. Figure $9 \mathrm{a}, \mathrm{b}$ shows a reduction of E-cadherin expression in T84SF cells compared to parental cells both at RNA and protein levels, as evidenced by reverse transcription-polymerase chain reaction (RT-PCR) semiquantitative and Western blot analyses, respectively. When we determined the levels of $\beta$-catenin in the two cell lines, we found a less significant reduction of protein expression in T84SF cells with respect to the parental cells (Fig. 9c), whereas there was a clear difference in the cellular localization. Confocal images show a distinct membranous $\beta$-catenin staining of T84 cells, while a cytoplasmic and nuclear localization was observed in selected T84SF cells (Fig. 9d).

Bcl- $\mathrm{X}_{\mathrm{L}}$ expression in T84-and T84SF-derived metastasis and in vitro cell cultures

To assess the expression of $\mathrm{Bcl}-\mathrm{X}_{\mathrm{L}}$ in parental and selected T84 cells, we next carried out a comparative analyses at both mRNA and protein levels. As shown in Fig. 10a, the RT-PCR semiquantitative analysis showed a higher Bcl- $\mathrm{X}_{\mathrm{L}}$ mRNA level in T84SF than in T84 cells. Moreover, Western blot analysis revealed that expression of Bcl- $\mathrm{X}_{\mathrm{L}}$ protein was also markedly increased in metastatic T84SF cells compared with parental cells (Fig. 10b). To confirm 
Fig. 7 Representative transmission electron micrographs of the cancer cells in the nests. Cells frequently form intercellular lumina that are sealed by specialized junctions and, frequently, desmosomes (arrowheads) tether the plasma membranes $(\mathbf{a}, \mathbf{b}, \mathbf{c}, \mathbf{e}, \mathbf{h})$. The cell membranes can be seen forming numerous folds and invaginations or tiny processes that deeply indent the cytoplasm $(\mathbf{e}, \mathbf{h}, \mathbf{i})$. Long microvilli project into the luminal surface of tumor cells $(\mathbf{b}, \mathbf{c})$; a high-power view of microvilli with a core of microfilaments is shown in $\mathbf{d}$. Figure c shows a lumen with a large remnant of cells. Membrane-bound dense granules, mitochondria (f), and myelin figures (g) can be also observed. $m$ Mitochondria, $l$ lumen. Scale bars $1 \mu \mathrm{m}(\mathbf{c}, \mathbf{e})$, $0.5 \mu \mathrm{m}(\mathbf{a}, \mathbf{b}, \mathbf{d}, \mathbf{f}-\mathbf{i})$
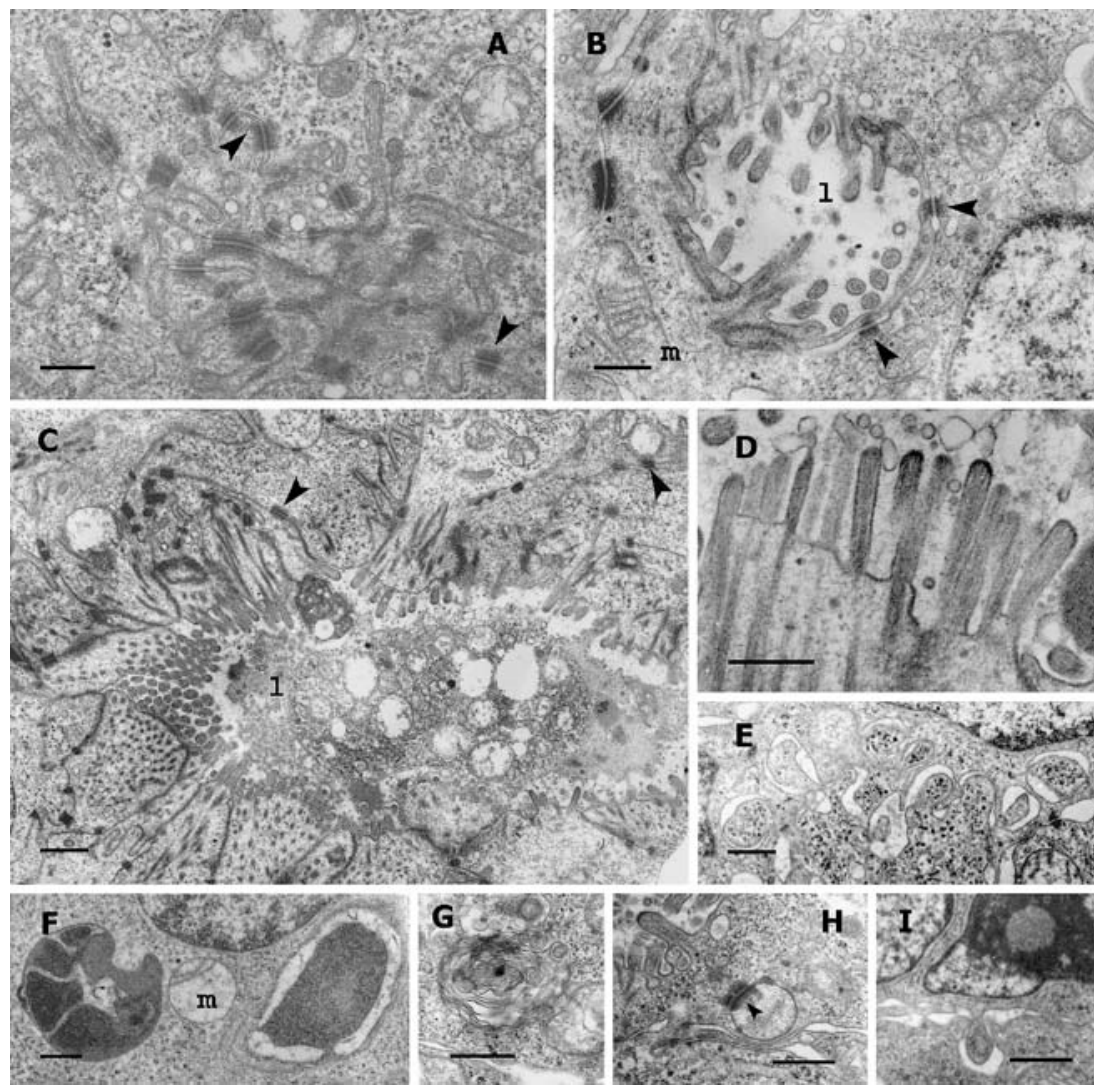

these results, we performed an immunohistochemical staining of Bcl- $\mathrm{X}_{\mathrm{L}}$ protein on the two cell lines and on corresponding lung metastatic foci. Figure $11 \mathrm{a}, \mathrm{b}$ illustrates the $\mathrm{Bcl}-\mathrm{X}_{\mathrm{L}}$ staining patterns on cultured cells and tissue sections, respectively. The images show a higher Bcl- $\mathrm{X}_{\mathrm{L}}$ expression in T84SF cells and related metastasis compared to the parental T84 cell line and tissues, in which a weak immunoreactivity was observed. To further validate the reduced susceptibility of T84SF colon cancer cells to apoptosis, we analyzed the levels of one of the main apoptosis effectors, caspase-3. Western blot analysis showed a $35 \%$ decrease of caspase-3 in selected cells compared to parental T84 cells (Fig. 10c).

\section{Discussion}

The establishment and thorough characterization of cancer cell lines derived from experimental in vitro or in vivo selections allow the development of new approaches to understand specific steps of tumor progression and metastasis formation. We recently established a new metastasis model by selecting a colon cancer cell line (T84SF) through repeated cycles of adhesion to E-selectin expressing endothelial cells (EC). This cell line represents a good working model to investigate tumor-EC interactions during metastasis because it shows increased growth rate, chemoinvasivity, MMP production, diminished apoptosis,
Fig. 8 Mitotic figure in thin section of tumor cells in metastatic foci (a). The cell has a typical metaphase plate and a bipolar spindle; it maintains desmosomal junctions (framed area) with the other cells. Supernumerary centrioles in metastatic T84SF cell (b); at least ten centrioles can be observed. Note an intracellular lumen with welldeveloped microvilli. Scale bars $1 \mu \mathrm{m}$ (a), $0.5 \mu \mathrm{m}$ (b). $l$ Lumen, $m$ mitochondria
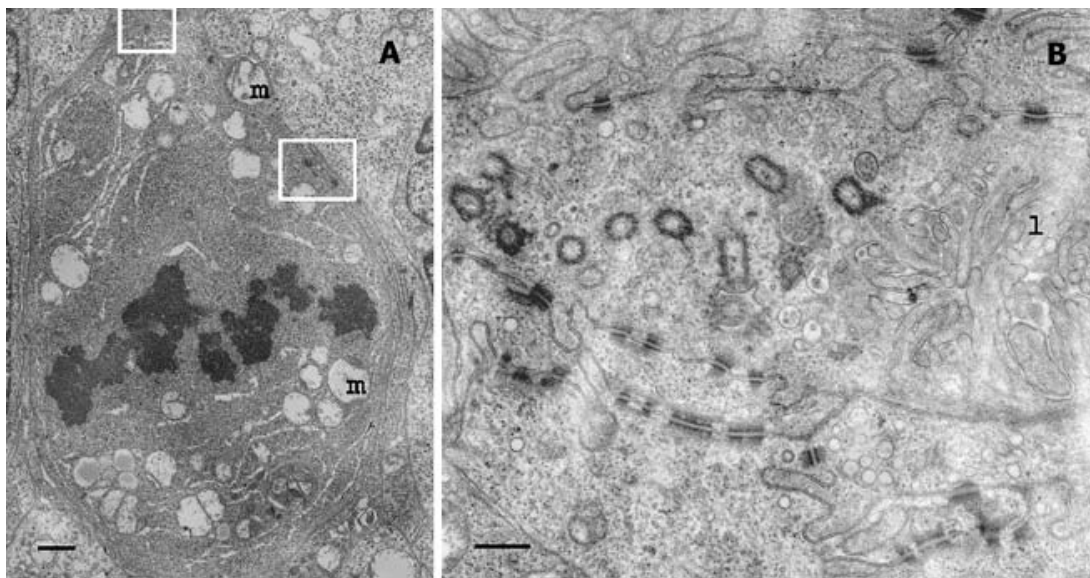


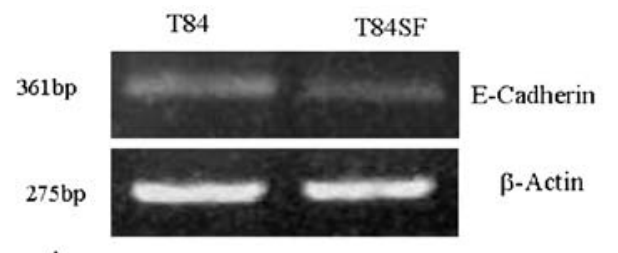

A

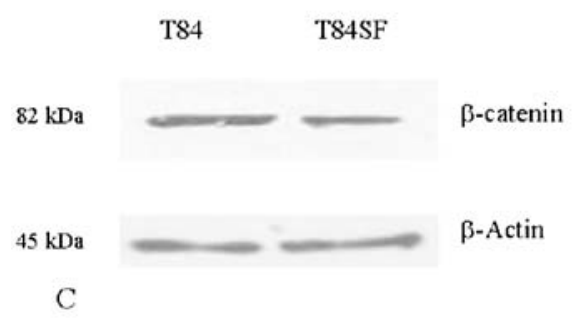

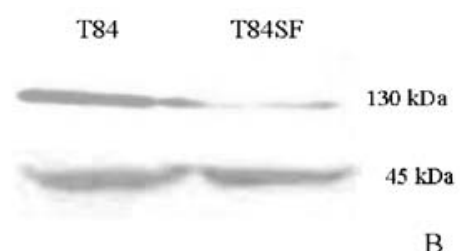

T84

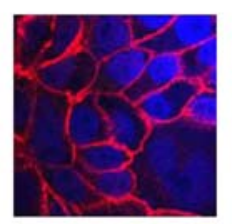

Fig. 9 E-cadherin expression and $\beta$-catenin localization. a Semiquantitative RT-PCR of E-cadherin and actin used as standard (lowerpanel). b Western blot analysis for evaluation of E-cadherin protein expression. c Western blot analysis for evaluation of $\beta$ catenin and actin protein evaluation, upper and lowerpanels, respectively. Fifty micrograms of cell lysates was loaded for both
T84 and T84SF cells. These results are representative of at least three different experiments. d Confocal laser scanning microscopy showing staining for $\beta$-catenin. Note that in T84SF cells, $\beta$-catenin is cytoplasmic and weakly nuclear, while in T84 cells, $\beta$-catenin is markedly localized at the cell membrane as well as a higher number of metastasis in nude mice compared to parental cells [4]. It has been reported that specific changes indicative of cancer process can be correlated with morphology, such as anchorage independent growth, invasiveness ability, and tumorigenicity [9, $29,43]$. The purpose of this work was to further detail our characterization of T84 and T84SF cells by adding an ultrastructural approach together with a biochemical investigation of molecular players involved in the higher invasive and metastatic phenotype of selected cells.

Comparison between the parental T84 colon cancer cells and the T84SF cells using transmission electron microscopy evidenced a greater complexity in selected cells as denoted by a marked pleomorphism of cell size and nuclei, shape, adhesion structures, and greater surface complexity. These morphological features were previously correlated with a greater metastatic potential in characterized cell lines such as $8701 \mathrm{BC}, \mathrm{MCF}-7$, and others [3, 9, 43].

T84SF cells exhibited, with respect to parental cells, numerous branched and randomly oriented protrusions, as well as a greater amount of microvilli of different size and shapes. Changes in the plasma membrane are probably of unique importance in the manifestation of several properties of metastatic phenotype. The functional significance of microvillous projections and blebs is poorly understood, but the variety of molecules found on such projections suggests a role in cell-cell interactions [5, 11, 16]. Several authors have shown that immortalized or transformed tumorigenic cell lines exhibited an increased number of microvillous projections compared with normal cells, and they also suggested that such projections may represent a morphological marker of neoplastic transformation $[10,30,36,47,48]$.
Fig. 10 Analyses of Bcl- $\mathrm{X}_{\mathrm{L}}$ and caspase 3 expression in T84 and T84SF cells. a Semi-quantitative RT-PCR of Bcl- $\mathrm{X}_{\mathrm{L}}$ and actin used as standard (lowerpanel). b Western blot analysis for evaluation of $\mathrm{Bcl}-\mathrm{X}_{\mathrm{L}}$ protein expression. Fifty microgram of cell lysate was loaded for both T84 and T84SF cells. This result is representative of at least three different experiments. c Lysates from T84 and T84SF cells were evaluated for caspase 3 expression by Western blot analysis. A $30 \%$ decrease in the amount of this apoptotic effector was observed in T84SF cells compared to parental ones

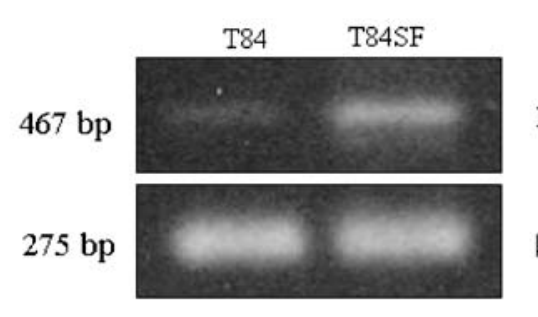

A

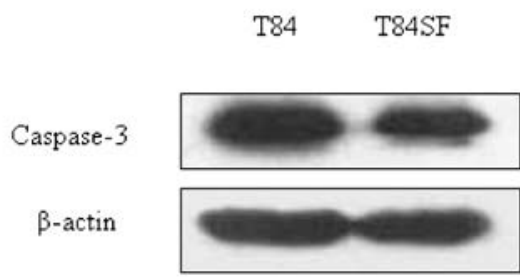

$32 \mathrm{kDa}$

$45 \mathrm{kDa}$

C 
T84

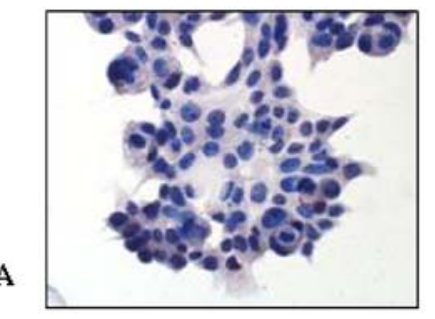

$\mathrm{T} 84$

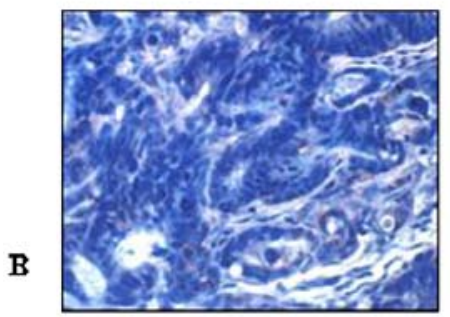

T84SF

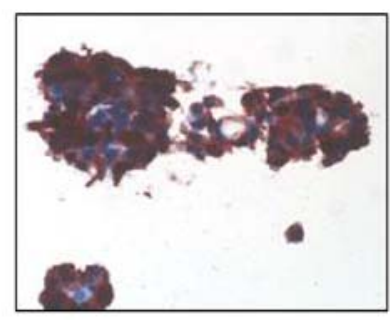

T84SF

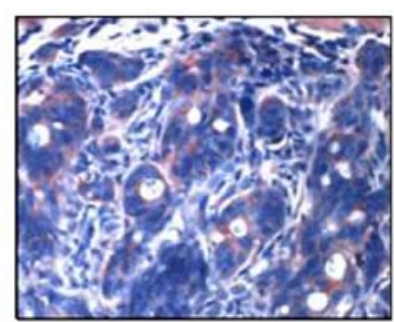

Fig. 11 a Immunohistochemical staining of $\mathrm{Bcl}-\mathrm{X}_{\mathrm{L}}$ on the two cell lines and $\mathbf{b}$ on corresponding lung metastatic foci

T84 cells have been shown to keep in culture several differentiated traits such as the ability to form functional tight junctions and desmosomes [35]. Our results confirm and extend these observations on samples derived from metastases formed by i.v. injection of cells in nude mice vein tail. Both cell lines produced multicellular aggregates displaying an acinar organization with well-developed apico-lateral junctional complexes. The metastases of colorectal adenocarcinomas often show histopathological features of the primary tumor and exhibit well-organized epithelial structures despite the acquisition of invasive properties and mesenchyme-like phenotypes during tumor progression. Such observations suggest that neoplastic cells may recover, probably influenced by local microenvironment, the same differentiated epithelial growth patterns characteristics of primary site [8].

In this scenario, the presence of regular junctional complexes in T84SF selected cells, although it may look incongruous with the more malignant phenotype of these cells, finds (1) a rationale in the procedure we adopted to select the cells and (2) confirmation from data obtained by other groups.

It is well-known that modifications in cancer cell adhesion play an important role in tumor progression, invasiveness, and metastasis [31]. Initially, a decrease in homotypic and heterotypic cancer cell adhesion, caused by the reduced expression of adhesion molecules and elevated activity of proteases including numerous metalloproteinases, promotes their escape from the primary tumor and intravasation [37]. During post-intravasation steps, however, the increased ability of blood-borne metastatic cells to form new heterotypic and homotypic adhesive interactions could be critically important for establishing secondary lesions in distant tissues and organs [42]. In several different types of cancer, the in vivo selection of tumor cells for high metastatic potential resulted in a selection of malignant cells exhibiting increased homotypic aggregation properties [2, 22]. In addition, cancer cell lines selected in vitro for enhanced homotypic aggregation kinetics demonstrated significantly higher in vivo experimental metastatic potential than parental cells [54]. An intriguing finding is the different cellular localization of $\beta$-catenin concomitant to a loss of plasma membrane-associated Ecadherin in T84SF cells compared to the parental T84 cells. A number of evidences show that delocalization of $\beta$ catenin is involved in tumor progression, and nuclear $\beta$ catenin may regulate target genes, such as matrilysin, CD44, uPAR, and fibronectin [27]. Qi et al. [45] recently showed that during transendothelial migration of melanoma cells, Src activation leads to the phosphorylation of $\mathrm{N}$ cadherin and subsequent dissociation of $\beta$-catenin. It is interesting to note that we previously demonstrated that T84SF cells have an increased Src activity and our present data on cytoplasmic and nuclear localization of $\beta$-catenin fit well with the possibility of this protein having a role in transendothelial migration of colon cancer cells. Therefore, our data strengthen the evidence that metastatic cells are able to modulate adhesive abilities during tumor progression, thus representing a facilitator mechanism in metastasis formation.

We have previously demonstrated a marked difference in the tumorigenicity and metastasis formation of T84 and T84SF cells [4]. T84SF cells have been shown having a higher growth rate in vitro than T84 parental cells. This is consistent with our ultrastructural observations of an increased number of mitotic figures, as well as of supernumerary centrioles in metastatic foci formed by T84SF cells. It is intriguing that amplification of the centrosome has been found in numerous forms of cancers [56]. This higher proliferation rate is associated with a decrease in apoptosis and related with an in vitro and in vivo augment of antiapoptotic molecules such as Bcl- $\mathrm{X}_{\mathrm{L}}$. Aberration in regulation of apoptosis has been recognized as an important mechanism in oncogenesis and tumor progression [24]. Different authors have evidenced that $\mathrm{Bcl}-\mathrm{X}_{\mathrm{L}}$ overexpression may enhance metastatic potential by counteracting the proapoptotic signals in the microenvironment, thus favoring the successful development of metastasis in specific organs $[17,38]$. We demonstrated that T84SF cells express, at mRNA and protein levels, both in vitro and in lung metastatic foci a greater amount of $\mathrm{Bcl}-\mathrm{X}_{\mathrm{L}}$ compared to T84 parental cells. It is known that the expression of Bcl- $\mathrm{X}_{\mathrm{L}}$ prevents the redistribution of cytochrome $\mathrm{c}$ from mitochondria to cytosol, a prominent requisite for caspase activation and apoptosis [33]. In accordance, we found a decreased amount of caspase-3 in T84SF cells with respect to the parental cells. Our results stress the involvement of $\mathrm{Bcl}-\mathrm{X}_{\mathrm{L}}$ in metastasis formation pointing to a role of the interaction of cancer cell to endothelial cells in the modulation of anti-apoptotic molecules.

Another ultrastructural feature we observed by analysis of T84 and T84SF cancer cells was the striking surface activity in T84 selected cells as testified by the release of membrane vesicles. The release of vesicles from living cells is considered to be a normal physiological process, 
but it is particularly active in proliferating cells, such as cancer cells where it can occur continuously, and is often related to enhanced proteolytic activity [55]. It is wellestablished that tumor cells use proteolytic activity to modify their environment; these enzymes may include tumor cell surface molecules or soluble molecules [15]. Proteases such as MMP-2, MMP-9, and u-PA were shown to play an active role in colon cancer invasion and metastasis [40]; positivity for MMP-2 expression was found more frequently in colon carcinoma with a more aggressive phenotype [39]. Previous investigations have demonstrated the presence of these molecules in membrane vesicles shed from different tumor cell lines, including melanoma, breast, ovarian, and fibrosarcoma cancer cell lines, while few information are available in colon cancer cell lines $[13,14,21,53]$. Although the process of shedding remains unclear, it has been associated with the release of growth factors, tumor antigens, increased cellular invasiveness, and suppression of immune surveillance. It is interesting to note that the present data show the presence of lytic bands likely corresponding to the activated forms of MMP-2 and MMP-9 in vesicles of both T84 and T84SF cells. These results fit well with the specific role described for vesicles in proliferating and invasive cancer cells [6]. We have previously reported that the increased invasiveness of T84SF cells was associated to a higher MMP-2 lytic activity than in parental cells. We believe that the major amount of vesicles shed by T84SF cells may explain the invasive phenotype of these cells. Moreover, to better understand the molecular events regulating the invasiveness of T84SF cells, we should investigate the role of other enzymes involved in extracellular matrix degradation such as other MMPs (stromalisin, matrilysin) or serine proteases.

To examine the cellular signaling underlying the phenotypic modifications evidenced in T84SF cells, we studied different interconnected cellular signaling known to be involved at various levels in cell proliferation and survival: protein tyrosine phosphorylation, MAPK, and AKT activation. The level of phosphorylation within a cell is a reflection of the balance between kinase and phosphatase activities. It is now well-established that tyrosine kinases play a central role in signal transduction, acting as relay points for a complex network of interdependent signaling molecules that ultimately lead to dramatic changes in tumor growth and survival, development, and metastasis [7]. Many growth factors have been reported to modulate metastasis-related phenotypes through the activation of receptor tyrosine kinase involving Ras/MAPK signal pathway [28]. A vast body of literature has documented the involvement of the AKT kinase as a final effector in the modulation of cell survival [20]. The complex nature of these interactions continues to be a challenge for the cancer biologist. Proper dissection and analysis of all these signaling systems hold the key for elucidating which target molecules are the most credible for the design of future successful therapeutics. The present data demonstrate the following: (1) T84SF cells undergo an increase in cytoplasmic and nuclear tyrosine-phosphory- lated proteins, as shown by immunofluorescence analysis; (2) a striking difference in ERK $1 / 2$ phosphorylation between parental and selected cells; and (3) a 20\% increase in AKT phosphorylation in T84SF cells compared to T84 cells.

Abdel-Ghany et al. [1] have proven that, in a model of lung colonization by B16-F10 cells, the interaction of cancer cells to the endothelium is mediated by $\beta 4$ integrin ligation to the lung endothelial $\mathrm{Ca}^{2+}$-activated chloride channel protein CLCA1, and that this interaction leads to the activation of downstream signaling to extracellular signal-regulated kinase. It has been reported that the activation of the ERK1/2 pathway in hematopoietic cells leads to transcriptional activation of AP-1 and AP-1-dependent Bcl- $X_{L}$ gene expression [52], while inhibition of ERK1/2 causes downregulation of Bcl-family proteins in human intestinal epithelial cells [26]. In a similar model of cells derived by colon mucosa, Sanders and Basson [49] showed that the collagen-mediated spreading and migration functions were dependent on ERK activation and that phosphorylation of ERK 1/2 required Src activity, thus suggesting that ERK is downstream of Src-mediated signaling pathway. Our present data show an increased ERK phosphorylation in T84SF cells compared to T84 parental cells. We previously demonstrated that the expression of the metastatic phenotype is correlated in T84SF cells with an augmentation of Src activity. Further work is necessary to investigate the correct correlation of these two pathways during transendothelial colon cancer migration.

AKT regulates a number of critical cellular pathways, including those leading to cellular proliferation and inhibition of apoptosis [20]. The survival signals of AKT upon its phosphorylation and activation are mediated in part via identified downstream targets of this kinase. Phosphorylation of BAD, Caspase 9, and Forkhead transcription factor by AKT suppresses the proapoptotic function of these proteins. Sekharam et al. [51] demonstrated that overexpression in colon cancer cells of insulin-like growth factor 1 and insulin-like growth factor 1 receptor causes the activation of AKT and upregulation at the transcriptional level of Bcl- $\mathrm{X}_{\mathrm{L}}$, with a consequent increase in expression of Bcl- $X_{L}$ protein. We have found a $20 \%$ increase in AKT phosphorylation in T84SF cells compared to the parental cells. These data, together with our results on $\mathrm{Bcl}-\mathrm{X}_{\mathrm{L}}$ expression, increased ERK activation and $\beta$-catenin localization bring us to speculate that our selection procedure has determined the isolation of a clone with specific overexpressed signaling pathways leading to the expression of a metastatic phenotype. Further work is in progress to identify the molecules whose levels in tyrosine phosphorylation are modulated in T84SF cells and the specific processes affected by these important signaling pathways.

In conclusion, our findings indicate that appropriate phenotypic features and critical cellular signaling have been retained by T84 parental and T84SF selected cells despite long-term culture in vitro and the selection procedure.

These cell lines therefore represent a step forward in the development of appropriate models in vitro and in vivo 
to investigate the process of extravasation during colon cancer progression.

Acknowledgements This work was supported by grants from the Italian Ministero della Istruzione, della Università e della Ricerca Scientifica $60 \%$ (MIUR) to R.A, M.A.D, A.M.F and G.D.L and by the Associazione Italiana per la Ricerca sul Cancro (AIRC) to R.A and G.D.L.

We thank Prof. F. Aragona for helpful discussions on the ultrastructural pathology of metastatic colonies.

Riccardo Alessandro and Maria Antonietta Di Bella contributed equally to this work.

Francesca Damiani and Chiara Corrado are $\mathrm{PhD}$ students in Immunopharmacology at the University of Palermo.

\section{References}

1. Abdel-Ghany M, Cheng H, Elble R, Pauli B (2002) Focal adhesion kinase activated by B4 integrin ligation to mCLCA1 mediates early metastatic growth. J Biol Chem 277: 34391-34400 (Sep 13)

2. Al-Mehdi A, Tozawa K, Fisher A, Shientag L, Lee A, Muschel RJ (2000) Intravascular origin of metastasis from the proliferation of endothelium-attached tumor cells: a new model for metastasis. Nat Med 6:100-102

3. Alessandro R, Minafra S, Pucci-Minafra I, Onisto M, Garbisa S, Melchiori A, Tetlow L, Woolley D (1993) Metalloproteinase and TIMP expression by the human breast carcinoma cell line 8701-BC. Int J Cancer 55:250-255

4. Alessandro R, Flugy A, Russo D, Stassi G, De Leo A, Corrado C, Alaimo G, De Leo G (2005) Identification and phenotypic characterization of a subpopulation of T84 human colon cancer cells, after selection on activated endothelial cells. J Cell Physiol 203:261-272

5. Berlin C, Bargatze R, Campbell JJ, von Andrian U, Szabo M, Hasslen S, Nelson R, Berg E, Erlandsen S, Butcher E (1995) Alpha 4 integrins mediate lymphocyte attachment and rolling under physiologic flow. Cell 80:413-422

6. Black P (1980) Shedding from the cell surface of normal and cancer cells. Adv Cancer Res 1:75-197

7. Blume-Jensen P, Hunter T (2001) Oncogenic kinase signalling. Nature 411:355-365

8. Brabletz T, Jung A, Reu S, Porzner M, Hlubek F, Kunz-Schughart L, Knuechel R, Kirchner T (2001) Variable beta-catenin expression in colorectal cancers indicates tumor progression driven by the tumor environment. Proc Natl Acad Sci USA 98:10356-10361

9. Calaf G, Russo J, Tait L, Estrad S, Alvarado ME (2000) Morphological phenotypes in neoplastic progression of human breast epithelial cells. J Submicrosc Cytol Pathol 32:83-96

10. Calaf G, Alvarado M, Hei T (2005) Beta catenin is associated with breast cancer progression in vitro. Int J Oncol 26:913-921

11. Carpen O, Pallai P, Staunton D, Springer T (1992) Association of intercellular adhesion molecule-1 (ICAM-1) with actincontaining cytoskeleton and alpha-actinin. J Cell Biol 118: 1223-1234

12. Dolo V, Pizzurro P, Ginestra A, Vittorelli M (1995) Inhibitory effects of vesicles shed by human breast carcinoma cells on lymphocyte $3 \mathrm{H}$-thymidine incorporation, are neutralised by anti TGF-beta antibodies. J Submicrosc Cytol Pathol 27:535-541

13. Dolo V, Ginestra A, Cassara D, Violini S, Lucania G, Torrisi MR, Nagase H, Canevari S, Pavan A, Vittorelli ML (1998) Selective localization of matrix metalloproteinase 9, beta1 integrins, and human lymphocyte antigen class I molecules on membrane vesicles shed by $8701-\mathrm{BC}$ breast carcinoma cells. Cancer Res 58:4468-4474
14. Dolo V, D'Ascenzo S, Violini S, Pompucci L, Festuccia C, Ginestra A, Vittorelli, M, Canevari S, Pavan A (1999) Matrixdegrading proteinases are shed in membrane vesicles by ovarian cancer cells in vivo and in vitro. Clin Exp Metastasis 17:131-140

15. Egeblad M, Werb Z (2002) New functions for the matrix metalloproteinases in cancer progression. Nat Rev Cancer 2: 161-174

16. Erlandsen S, Hasslen S, Nelson R (1993) Detection and spatial distribution of the beta 2 integrin (Mac-1) and L-selectin (LECAM-1) adherence receptors on human neutrophils by high-resolution field emission SEM. J Histochem Cytochem 41:327-333

17. Espana L, Fernandez Y, Rubio N, Torregrosa A, Blanco J, Sierra A (2004) Overexpression of Bcl-xL in human breast cancer cells enhances organ-selective lymph node metastasis. Breast Cancer Res Treat 87:33-44

18. Fidler I (1990) Critical factors in the biology of human cancer metastasis: twenty-eighth G.H.A. Clowes memorial award lecture. Cancer Res 50:6130-6138

19. Fidler I (2003) The pathogenesis of cancer metastasis: the 'seed and soil' hypothesis revisited. Nat Rev Cancer 3:453-458

20. Franke T, Kaplan D, Cantley L (1997) PI3K: downstream AKTion blocks apoptosis. Cell 88:435-437

21. Ginestra A, La Placa M, Saladino F, Cassara D, Nagase H, Vittorelli M (1998) The amount and proteolytic content of vesicles shed by human cancer cell lines correlates with their in vitro invasiveness. Anticancer Res 18:3433-3437

22. Glinsky V, Glinsky G, Rittenhouse-Olsen K, Huflejt M, Glinskii O, Deutscher S, Quinn T (2001) The role of Thomsen-Friedenreich antigen in adhesion of human breast and prostate cancer cells to the endothelium. Cancer Res 61: $4851-4857$

23. Graves L, Ariztia E, Navari J, Matzel H, Stack M, Fishman D (2004) Proinvasive properties of ovarian cancer ascites-derived membrane vesicles. Cancer Res 64:7045-7049

24. Hanahan D, Weinberg R (2000) The hallmarks of cancer. Cell 100:57-70

25. Harada K, Nishizaki T, Ozaki S, Kubota H, Ito H, Sasaki K (1998) Intratumoral cytogenetic heterogeneity detected by comparative genomic hybridization and laser scanning cytometry in human gliomas. Cancer Res 58:4694-4700

26. Harnois C, Demers M, Bouchard V, Vallee K, Gagne D, Fujita N, Tsuruo T, Vezina A, Beaulieu J, Cote A, Vachon P (2004) Human intestinal epithelial crypt cell survival and death: Complex modulations of Bcl-2 homologs by Fak, PI3-K/Akt-1, MEK/Erk, and p38 signalling pathways. J Cell Physiol 198: 209-222

27. Harris T, Peifer M (2005) Decisions, decisions: beta-catenin chooses between adhesion and transcription. Trends Cell Biol $15: 234-247$

28. Hartmann G, Weidner K, Schwarz H, Birchmeier W (1994) The motility signal of scatter factor/hepatocyte growth factor mediated through the receptor tyrosine kinase met requires intracellular action of Ras. J Biol Chem 269(35):21936-21939

29. Hewitt RE, McMarlin A, Kleiner D, Wersto R, Martin P, Tsokos M, Stamp GW, Stetler-Stevenson WG (2000) Validation of a model of colon cancer progression. J Pathol 192:446-454

30. Jackson S, Strausbauch P, Finley J, Laich D, Hewan-Lowe K (2003) Desmosomes and microvilli mean a lot: diagnosis of neoplasms of unknown origin using electron microscopy. Ultrastruct Pathol 27:155-161

31. Jothy S, Munro S, LeDuy L, McClure D, Blaschuk O (1995) Adhesion or anti-adhesion in cancer: what matters more? Cancer Metastasis Rev 14:363-376

32. Kim J, Wieckowski E, Taylor D, Reichert T, Watkins S, Whiteside T (2005) Fas ligand-positive membranous vesicles isolated from sera of patients with oral cancer induce apoptosis of activated T lymphocytes. Clin Cancer Res 11:1010-1020

33. Kluck R, Bossy-Wetzel E, Green D, Newmeyer D (1997) The release of cytochrome $\mathrm{c}$ from mitochondria: a primary site for Bcl-2 regulation of apoptosis. Science 275:1132-1136 
34. Laferriere J, Houle F, Huot J (2004) Adhesion of HT-29 colon carcinoma cells to endothelial cells requires sequential events involving E-selectin and integrin beta4. Clin Exp Metastasis 21:257-264

35. Liu Y, Nusrat A, Schnell FJ, Reaves TA, Walsh S, Pochet M, Parkos CA (2000) Human junction adhesion molecule regulates tight junction resealing in epithelia. J Cell Sci 113(Pt 13): 2363-2374 (July)

36. Malick L, Langenbach R (1976) Scanning electron microscopy of in vitro chemically transformed mouse embryo cells. J Cell Biol 68:654-664

37. Martin G (2003) Cell signalling and cancer. Cancer Cell 4: 167-174

38. Martin S, Ridgeway A, Pinkas J, Lu Y, Reginato M, Koh E, Michelman M, Daley G, Brugge J, Leder P (2004) A cytoskeleton-based functional genetic screen identifies Bcl-xL as an enhancer of metastasis, but not primary tumor growth. Oncogene 23:4641-4645 (Jun 3)

39. Matsuyama Y, Takao S, Aikou T (2002) Comparison of matrix metalloproteinase expression between primary tumors with or without liver metastasis in pancreatic and colorectal carcinomas. J Surg Oncol 80:105-110

40. Mook O, Frederiks W, Van Noorden C (2004) The role of gelatinases in colorectal cancer progression and metastasis. Biochim Biophys Acta 1705:69-89

41. Nicolson G, Menter D, Herrmann J, Yun Z, Cavanaugh P, Marchetti D (1996) Brain metastasis: role of trophic, autocrine, and paracrine factors in tumor invasion and colonization of the central nervous system. Curr Top Microbiol Immunol 213: 89-115

42. Orr F, Wang H (2001) Tumor cell interactions with the microvasculature: a rate-limiting step in metastasis. Surg Oncol Clin N Am 10:357-381

43. Pucci-Minafra I, Minafra S, Alessandro R, Faccini AM (1989) An ultrastructural evaluation of cell heterogeneity in invasive ductal carcinomas of the human breast. II. An in vitro study. J Submicrosc Cytol Pathol 21:489-499

44. Putz E, Witter K, Offner S, Stosiek P, Zippelius A, Johnson J, Zahn R, Riethmuller G, Pantel K (1999) Phenotypic characteristics of cell lines derived from disseminated cancer cells in bone marrow of patients with solid epithelial tumors: establishment of working models for human micrometastases. Cancer Res 59:241-248

45. Qi J, Wang J, Romanyuk O, Siu C (2005) Involvement of Src family kinases in N-cadherin phosphorylation and \{beta\}catenin dissociation during transendothelial migration of melanoma cells. Mol Biol Cell 17(3):1261-1272
46. Radinsky R (1995) Modulation of tumor cell gene expression and phenotype by the organ-specific metastatic environment. Cancer Metastasis Rev 14:323-338

47. Rovensky Y, Komissarova E, Topol L, Kisseljov F (1992) Changes in surface relief of suspended cells are morphological signs of the initial stage of neoplastic transformation in fibroblastic monolayer cultures. Cell Biol Int Rep 16:557-565 (Jun)

48. Russo J, Tait L, Russo I (1991) Morphological expression of cell transformation induced by c-Ha-ras oncogene in human breast epithelial cells. J Cell Sci 99(Pt 2):453-463 (Jun)

49. Sanders M, Basson M (2004) Collagen IV regulates Caco-2 migration and ERK activation via alpha1beta1- and alpha2beta1-integrin-dependent Src kinase activation. Am J Physiol Gastrointest Liver Physiol 286:G547-G557

50. Seddighzadeh M, Zhou J, Kronenwett U, Shoshan M, Auer G, Sten-Linder M, Wiman B, Linder S (1999) ERK signalling in metastatic human MDA-MB-231 breast carcinoma cells is adapted to obtain high urokinase expression and rapid cell proliferation. Clin Exp Metastasis 17:649-654

51. Sekharam M, Zhao H, Sun M, Fang Q, Zhang Q, Yuan Z, Dan H, Boulware D, Cheng J, Coppola D (2003) Insulin-like growth factor 1 receptor enhances invasion and induces resistance to apoptosis of colon cancer cells through the $\mathrm{Akt} / \mathrm{Bcl}-\mathrm{x}(\mathrm{L})$ pathway. Cancer Res 63:7708-7716

52. Sevilla L, Zaldumbide A, Pognonec P, Boulukos K (2001) Transcriptional regulation of the bcl-x gene encoding the antiapoptotic Bcl-xL protein by Ets, Rel/NF-kB, STAT and AP-1 transcription factor families. Histol Histopathol 16:595-601

53. Taraboletti G, D'Ascenzo S, Borsotti P, Giavazzi R, Pavan A, Dolo V (2002) Shedding of the matrix metalloproteinases MMP-2, MMP-9, and MT1-MMP as membrane vesicleassociated components by endothelial cells. Am J Pathol 160: 673-680

54. Updyke T, Nicolson G (1986) Malignant melanoma cell lines selected in vitro for increased homotypic adhesion properties have increased experimental metastatic potential. Clin Exp Metastasis 4:273-284

55. Vittorelli M (2003) Shed membrane vesicles and clustering of membrane-bound proteolytic enzymes. Curr Top Dev Biol $54: 411-432$

56. Wang Q, Hirohashi Y, Furuuchi K, Zhao H, Liu Q, Zhang H, Murali R, Berezov A, Du X, Li B, Greene M (2004) The centrosome in normal and transformed cells. DNA Cell Biol $23: 475-489$

57. Wijnhoven B, Dinjens W, Pignatelli M (2000) E-cadherincatenin cell-cell adhesion complex and human cancer. $\mathrm{Br} J$ Surg 87:992-1005 